\title{
Public Health Aspects' Assessment Tool for Urban Projects, According to the Urban Health Approach
}

\author{
Stefano Capolongo, Maddalena Buffoli, Erica Isa Mosca, Daniela Galeone, \\ Roberto D'Elia and Andrea Rebecchi
}

\begin{abstract}
As part of the CCM2017 project titled "Urban Health," this paper describes the experience of developing and testing a multi-criteria, quali-quantitative assessment framework for Public Health aspects. The tool aims to evaluate urban transformation and regeneration actions, according to Urban Health strategies.
\end{abstract}

Keywords Urban health · Public health · Healthy urban planning and design strategies $\cdot$ Evaluation tool $\cdot$ Multi-criteria analysis

\section{Introduction}

Planning and management actions in urban contexts provide several opportunities for the protection and promotion of Public Health. Indeed, health conditions depend especially on environmental, economic and social factors (Fehr and Capolongo 2016), which are influenced by a correct design and management of the living environment. The concept of Urban Health has been introduced since the beginning of 2000, based on the definition of Healthy City which refers to the "urban contexts able to support and improve constantly the physical environment and the social context, encouraging the development of economic and social resources, allowing people to mutually support each other in the development of daily life activities." (WHO 2016). From this concept derives the Urban Health strategy, which refers to the relationship between health promotion, disease prevention and the different interrelations with urban factors (Talukder et al. 2015). Indeed, Urban Health represents a complex issue as the actions aimed at improving the living conditions

\footnotetext{
S. Capolongo $(\varangle) \cdot$ M. Buffoli $\cdot$ E. I. Mosca $\cdot$ A. Rebecchi

Architecture, Built Environment and Construction Engineering-ABC Department, Politecnico di Milano, Milan, Italy

e-mail: stefano.capolongo@polimi.it

D. Galeone · R. D'Elia

Direzione Generale della Prevenzione Sanitaria, Ministero della Salute, Rome, Italy
} 
of cities depend not only on the health sector, but also on urban planning decisions, as well on social, welfare, and education programs (Galea and Vlahov 2005).

In this regard, the Erice 50 Charter entitled "Strategies for Disease Prevention and Health Promotion in Urban Areas" by D'Alessandro et al. (2017b) defines ten goals useful to designers and policy makers, aimed to support the design of Healthy Cities. One of the most important goals for local government is the promotion of urban planning interventions that address citizens' healthy behavior and lifestyles (Capolongo et al. 2011; World Health Organization 2017).

Furthermore, the emerging environmental, social, and economic criticisms of the last years have given rise to a need for more specific objectives aimed at achieving Salutogenic Cities (Capolongo et al. 2018). In particular, the new objectives for healthy design and urban planning strategies have been defined, such as environmental and social sustainability of urban areas; adaptation to climatic changes and cities' urban resilience (Hickman and Banister 2014); new responses to the population's needs (Croucher et al. 2012; Active Living Research 2015).

In this regard, the support of urban planning becomes an important task to promote and protect different aspects as the health, wellbeing, and social inclusion of individuals who are directly influenced by their relationship with the built environment. Processes of validation, monitoring, assessment and formulation of strategic decision-making processes, through the application of mathematical tools and systems, are the basis of city regeneration actions as well as urbanized territory governance and Public Health promotion (Capolongo et al. 2016). Multi-criteria evaluation tools, updated with innovative strategies to reach Urban Health purposes are, therefore, needed in order to support planners and designers to achieve a healthier scenario. However, tools which evaluate how the design of cities can have an impact on people's health are still difficult to compare and apply, and they are primarily focused on quality and urban sustainability, neglecting the direct and indirect Public Health implications.

For this reason, the research starts from the current need to investigate the most recent and common urban quality evaluation tools, in order to understand which of them adopt performance criteria with direct or indirect relationships with Urban Health.

Within this context, the paper describes the advancements in the development of a multi-criteria evaluation tool based on a set of performance criteria (Capolongo et al. 2015). The tool was developed by an interdisciplinary working group which includes researchers from the DABC and DAStU Departments of the Politecnico di Milano and technicians from the Health Prevention Department of the Local Health Authorities (LHA) of Milan (Capolongo et al. 2013). The evaluation tool was developed with the main purpose of providing support to guide urban transformation and fostering the elaboration of strategic decisions on new planning interventions (Coppola et al. 2016). In addition, it is also aimed at monitoring advancements by evaluating changes over time. However, after the application of the tool, the need of extending its scale of intervention, from a local to a national level, defines the basis on which to review and improve the assessment tool, which is carried on by the DABC of the Politecnico di Milano and by the LHA of Bergamo, thanks to the funds of the National Center 
for Disease Prevention and Control CCM2017 regarding the project titled "Urban Health: good practices for health impact assessment of urban and environmental redevelopment and regeneration interventions." (CUP: C42F17000330001).

\section{Methodology}

Urban Health is characterized by a plurality of social and qualitative aspects derived by the relation between the built environment and its influence on Public Health and wellbeing. For this reason, multi-criteria analysis (Roy 2013) is adopted by the current research to systematically and scientifically develop the tool. This approach allows for both the analysis of the full range of aspects relating to a project and the simultaneous comparison of heterogeneous measures for evaluating a complex situation (Department for Communities and Local Government DCLG 2009). Furthermore, a performance-based approach characterizes the assessment method, aimed to overcome the traditional prescriptive regulations by means of the achievement of objectives based on urban quality. Finally, the direct contribution of experts in analyzing and evaluating projects was an essential component to guarantee new evidencebased knowledge. For this reason, LHA technicians were involved in both the tool development and the updating by means of brainstorming, aimed at discussing the most important criticisms emerging from the hygienic-sanitary evaluation of urban plans and projects (Capasso et al. 2018; Gola et al. 2017).

The research is developed through different phases, shown in the diagram (Fig. 1); after defining the main objectives to consider, a collection of best practices was supported by a literature review aimed to investigate the current and existing studies on urban quality evaluation methods and tools. A set of criteria was selected among the analyzed studies, fixing the basis for the development of the tool's framework and the evaluation method (Capolongo et al. 2016). The multi-criteria evaluation tool was applied and tested to have feedback on its effectiveness in two cities of the Lombardy region: in Milan since 2011 and for one year in Lecco. The reliability of the instrument was confirmed, while the applicability of certain evaluation criteria was considered critical. For these reasons, the tool is currently under review for an update and improvement of its criteria and performance scales, thanks to the funds provided by the CCM2017 project.

The on-going review will foster the possibility to apply the tool from local to national level and to increase public awareness regarding the relationship between Public Health and urban quality according to the Urban Health strategy (Rebecchi et al. 2016). 
Fig. 1 Methodology flow chart (authors' elaboration)

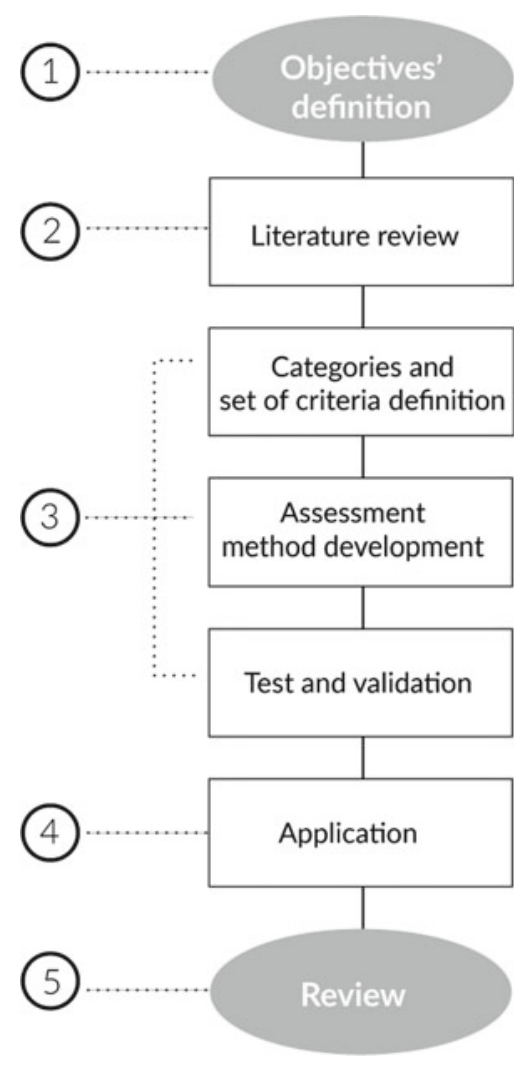

\section{Results}

A significant number of European initiatives, aimed at measuring the level of sustainability and urban quality using different sets of criteria, based on a variety of factors such as environmental, social, and economic issues were found. For this reason, the literature review was useful to collect data for the categories and criteria for the tool's development.

Articles were selected from online databases by using specific keywords. The studies, selected and compared by means of eligibility criteria, have been used to include or exclude articles from the analysis.

Specifically, the literature review considered the following projects and tools:

- Indicatori Comuni Europei. Verso un profilo di sostenibilità locale. Ambiente Italia.

- Progetto Città Sane. Comune di Milano.

- A healthy city is an active city: a physical activity planning guide, Who Europe.

- Healthy City Project Technical Working Group on City Health Profiles, City Health Profiles. 
- The Urban Audit. Toward the Benchmarking of Quality of Life in 58 European Cities. European Commission.

- Audit Commission Local Quality of Life Indicators supporting local communities to become sustainable. A guide to local monitoring to complement the indicators in the UK Government Sustainable Development Strategy, Office of the Deputy Prime Minister.

- Ecosistema Metropolitano, Ambiente Italia, Provincia di Milano.

- Green Building Tool—GBTool.

- Protocollo Itaca per la valutazione della qualità energetica ed ambientale di un edificio, Istituto ITACA.

- Progetto S.I.S.Te.R.

Furthermore, the most recent available neighborhood-level certification protocols were also included in the review. Starting from 46 selected studies, the eligibility criteria allowed researchers to reduce the analysis down to the following seven protocols: for America,

- LEED-ND. For Europe, the English protocol

- BREEAM for Communities, the French protocol

- HQE UPD, and the German protocol

- DGNB. For Asia, the Japanese protocol

- CASBEE UD and the protocol of members of the Persian Gulf

- GSAS. Finally, for Oceania, the Australian protocol

- GREEN STAR COMMUNITIES. All these tools were analyzed and compared in order to collect criteria that will form the evaluation framework of the instrument.

The multi-criteria evaluation tool, based on a set of performance criteria and aimed to promote Public Health purposes from the quality of the built environment, was developed in this way.

\subsection{The Multi-criteria Evaluation System}

The literature review, together with various brainstorming activities and focus groups with the technicians of the LHA of Milan, has allowed us to identify the 206 most frequently used criteria using the tools found in the literature, and to support the development of a new evaluation system.

The final assessment framework (Fig. 2) is formed of six thematic issues (environmental quality and wellbeing; waste; energy and renewable resources; mobility and accessibility; land use and functional mix; quality of urban landscape) and a set of 23 criteria, as Fig. 2 synthetizes.

Each criterion was developed in a specific evaluation data-record that includes the expected output to achieve, its impact on health (Oppio et al. 2016), a performance evaluation on both neighborhood and urban scale, a selection of best practices supported by pictures, notes and references. 


\begin{tabular}{|c|c|}
\hline Thematic issues & Criteria \\
\hline 1 Environmental quality and wellbeing & $\begin{array}{l}1 \text { Air } \\
2 \text { Noise } \\
3 \text { Water } \\
4 \text { Ionizing radiations }\end{array}$ \\
\hline 2 Waste & $\begin{array}{l}5 \text { Solid waste management } \\
6 \text { Liquid waste management }\end{array}$ \\
\hline 3 Energy and renewable resources & $\begin{array}{l}7 \text { Energy consumption and monitoring } \\
8 \text { Passive technical systems for sustainability } \\
9 \text { Active technical systems for sustainability }\end{array}$ \\
\hline 4 Mobility and accessibility & $\begin{array}{l}10 \text { Distances to parks and local services } \\
11 \text { Public transport system } \\
12 \text { Availability of pedestrian and bicycle paths } \\
13 \text { Links between existent mobility system and new settlements }\end{array}$ \\
\hline 5 Land use and functional mix & $\begin{array}{l}14 \text { Functional and social mix } \\
15 \text { Urban density } \\
16 \text { Filtering areas } \\
17 \text { Protection of sensitive users } \\
18 \text { Hazardous and nuisance activities }\end{array}$ \\
\hline 6 Quality of urban landscape & $\begin{array}{l}19 \text { Quality of outdoors areas } \\
20 \text { Urban equipment } \\
21 \text { Visual comfort } \\
22 \text { System of urban green areas } \\
23 \text { Parkings for inhabitants }\end{array}$ \\
\hline
\end{tabular}

Fig. 2 Assessment framework (elaboration by the authors)

In order to measure the achievement's level of the qualitative criteria, constructed attributes (Bouyssou et al. 2000) were used. The performance values are expressed with a qualitative score rating from 0 (inadequate performance) to 3 (good practice).

The current performance evaluation scale represents the basis of the evaluation report, as well as a guidelines manual for designers and urban planners with regards to Public Health (Table 1). Each score, defined by teams of experts, is explained through a reference judgment that points out the requirements that are mandatory for reaching the highest score. Since the score achieved by each thematic issue is given by the average of the scores gained in each criterion, the performance values of plans/projects are defined according to one of the following ranges:

- negative $(0 \leq$ performance value $\leq 1.5)$;

- $\operatorname{critical}(1.5<$ performance value $\leq 2.25)$;

- $\operatorname{good}(2.25<$ performance value $\leq 3)$.

The results of the tool are provided by different graphic means (Fig. 3) that underline strengths and weaknesses of the urban development proposals under evaluation. In particular, a spider diagram shows the score achieved by each thematic issue, while three histograms show: the overall score of the urban plan/project; the scores of the thematic issues and the score achieved by each criterion (Capolongo et al. 2015, 2016). 
Table 1 Performance judgments for environmental quality and wellbeing on a neighborhood-level for a healthy urban planning tool (elaboration by the authors)

\begin{tabular}{|c|c|c|}
\hline Issues & Criteria & Performance values \\
\hline \multirow[t]{2}{*}{ Air } & $\begin{array}{l}\text { Presence of pollution sources, coexistence of the } \\
\text { following strategies } \\
\text { - Location of sensitive users in protected areas } \\
\text { and far from the pollution sources } \\
\text { - Strategies for limiting emissions at source } \\
\text { and/or reducing the diffusion of pullutants }\end{array}$ & Good \\
\hline & $\begin{array}{l}\text { Presence of only one of the strategies listed above } \\
\text { Absence of the strategies listed above }\end{array}$ & Critical not sufficient \\
\hline \multirow[t]{2}{*}{ Noise } & $\begin{array}{l}\text { Presence of noise sources, introduction of the } \\
\text { following strategies } \\
\text { - Location of sensitive users in protected areas } \\
\text { and far from the noise sources } \\
\text { - Strategies for limiting noise at source and/or } \\
\text { reducing the noise transmission from fixed or } \\
\text { mobile sources }\end{array}$ & Good \\
\hline & $\begin{array}{l}\text { Presence of only one of the strategies listed above } \\
\text { Absence of the strategies listed above }\end{array}$ & Critical not sufficient \\
\hline \multirow[t]{2}{*}{ Water } & $\begin{array}{l}\text { Coexistence of the following strategies } \\
\text { - Efficient water supply system } \\
\text { - Reducing waste and saving drinking water }\end{array}$ & Good \\
\hline & $\begin{array}{l}\text { Presence of an efficient water supply system } \\
\text { Absence of the strategies listed above }\end{array}$ & Not sufficient critical \\
\hline \multirow[t]{2}{*}{$\begin{array}{l}\text { Ionizing } \\
\text { radiations/non } \\
\text { ionizing } \\
\text { radiations }\end{array}$} & $\begin{array}{l}\text { Presence and/or absence of possible sources of } \\
\text { ionizing/not ionizing radiations, coexistence of the } \\
\text { following strategies } \\
\text { - Location of sensitive users and users with } \\
\text { residence time higher than } 4 \mathrm{~h} \text { away from } \\
\text { ionizing/non ionizing radiations; absence of } \\
\text { sensitive users close to power lines } \\
\text { - Strategies aimed to remove or to mitigate } \\
\text { ionizing/not ionizing radiations }\end{array}$ & Good \\
\hline & $\begin{array}{l}\text { Presence of only one of the strategies listed above } \\
\text { Absence of the strategies listed above }\end{array}$ & Critical not sufficient \\
\hline
\end{tabular}

\subsection{Validation and Development}

The evaluation tool was applied in the Lombardy region by the LHA of Bergamo, Milan, and Lecco with the aim of evaluating the procedure to be able to extend its use in other contexts. In particular, the application took place in Milan since 2011 and it is still in use, and for one year the tool was tested in Lecco. From these analyses, although the reliability of the instrument was confirmed, the applicability of a number of evaluation criteria was considered critical or limited by a lack of information. 

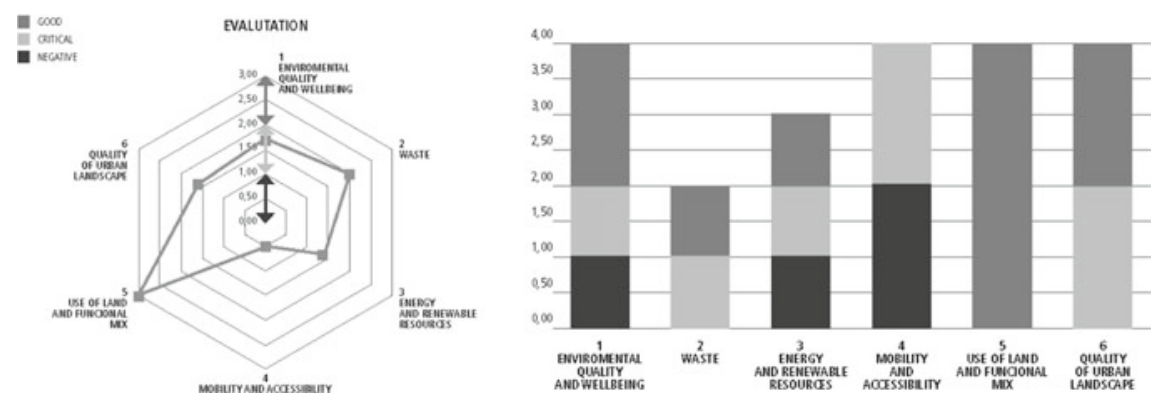

Fig. 3 Output of the evaluation through the different graphic means of the assessment tool (elaboration by the authors)

These results highlight the need to update certain criteria according to the new requirements of the Urban Health strategy (D'Alessandro et al. 2017a), and to introduce new ones, for instance regeneration of the abandoned areas and the contaminated site (ground and underground); geological, hydrogeological, and seismic risk prevention; social equity; universal design and design for all (European Institute for Design and Disability_EIDD 2004).

In particular, the last criteria refer to social wellbeing, since healthy cities are considered inclusive places, where planning and policy-making incorporate the views, voices, and needs of all communities (WHO 2016). This concept is assumed by the design for all strategy defined in 2004 by the European Institute for Design and Disability (EIDD), aimed to achieve cities where people diversity, social inclusion and equality represent the main drivers for Urban Health promotion (Mosca et al. 2019). Design for all's purpose is to develop functional and comfortable environments that can be used independently by the greatest number of users as possible, overcoming the concept of architectural barriers. The purpose is to provide the same experience of the space, even with various solutions, to different people, regardless of their abilities, disabilities, age, sex, and culture. The application of design for all concerns the involvement of a plurality of stakeholders (both experts and final users) from the beginning of the design process. This strategy is fundamental in order to understand and satisfy the physical, sensorial, and cognitive needs of the individuals by means of a prescriptive approach (Mosca et al. 2019).

Considering these new criteria, concerning the relationship between people's wellbeing and the quality of built environments, a review of the tool to make it more flexible and efficient in practice is required. After the update of the criteria, the following step will be to modify the performance scales and benchmarks of some criteria according to different territorial features. Furthermore, the outcomes of the survey suggest assigning different weights to the criteria in relation to their potential effects on Urban Health. 
For these reasons, the tool is currently under review in order to update and improve its criteria and the performance scales by means of a project of two years (20182020) entitled "Urban Health: good practices for health impact assessment of urban and environmental redevelopment and regeneration interventions." funded by the CCM, as previously mentioned.

The research team is coordinated by the Lombardy region (national proponent) and involves four Italian regions: Lombardy (LHA of Bergamo and ABC Department of the Politecnico di Milano); Piedmont (LHA3 of Turin and SCaDU, the regional epidemiology unit); Tuscany (LHA of Tuscany Nord Ovest); Apulia (LHA of Taranto).

The current review will foster the possibility of applying the tool from a local to a national level, and to increase public awareness regarding the connection between Public Health and urban quality according to the Urban Health strategy.

\section{Conclusions}

The review process both highlights the responsiveness of the evaluation tool to the current Urban Health issues and strengthens the effectiveness of the assessment process. Thus, in light of the most recent goals and requirements (D'Alessandro et al. 2015, 2016) the criteria review will provide several possibilities to expand the influence of the urban quality assessment tool from the local to national scale.

Furthermore, the overall contribution of the instrument includes, as one of its main objectives, increasing public awareness about the link between urban quality and Public Health, fostering the opportunities for a more effective relationship and training among designers (urban planners and architects) and Public Health professionals. Indeed, the instrument aims to be adopted both for supporting the assessment task of technicians of the LHA and as a guide for designers and planners in the design of interventions concerning social and healthy environments. The project funded by CCM2017, therefore, could be the opportunity to demonstrate new insights from the current review of the tool.

\section{References}

Active Living Research. (2015). Promoting activity-friendly communities. Active living research (pp. 3-7). San Diego, CA, USA.

Bouyssou, D., Marchant, T., Pirlot, M., Perny, P., Tsoukias, A., \& Vincke, P. (2000). Evaluation and decision models: A critical perspective (Vol. 32). Springer Science \& Business Media.

Capasso, L., Faggioli, A., Rebecchi, A., Capolongo, S., Gaeta, M., Appolloni, L., et al. (2018). Hygienic and sanitary aspects in urban planning: Contradiction in national and local urban legislation regarding public health. Epidemiologia e Prevenzione, 42(1), 60-64. https://doi.org/10. 19191/EP18.1.P060.016. 
Capolongo, S., Battistella, A., Buffoli, M., \& Oppio, A. (2011). Healthy design for sustainable communities. Annali di Igiene, 23(1), 43-53.

Capolongo, S., Buffoli, M., \& Oppio, A. (2015). How to assess the effects of urban plans on environment and health. Territorio, 73, 145-151.

Capolongo, S., Buffoli, M., Oppio, A., \& Rizzitiello, S. (2013). Measuring hygiene and health performance of buildings: a multidimensional approach. Annali di Igiene, 25(2), 151-157. https:// doi.org/10.7416/ai.2013.1917.

Capolongo, S., Lemaire, N., Oppio, A., Buffoli, M., \& Roue Le Gall, A. (2016). Action planning for healthy cities: The role of multi-criteria analysis, developed in Italy and France, for assessing health performances in land-use plans and urban development projects. Epidemiologia e Prevenzione, 40(3-4), 257-264. https://doi.org/10.19191/EP16.3-4.P257.093.

Capolongo, S., Rebecchi, A., Dettori, M., Appolloni, L., Azara, A., Buffoli, M., et al. (2018). Healthy design and urban planning strategies, actions, and policy to achieve Salutogenic Cities. International Journal of Environmental Research and Public Health, 15(12), 2698. https://doi. org/10.3390/ijerph15122698.

Coppola, L., Ripamonti, E., Cereda, D., Gelmi, G., Pirrone, L., \& Rebecchi, A. (2016). 20152018 Regional Prevention Plan of Lombardy (Northern Italy) and sedentary prevention: A crosssectional strategy to develop evidence-based programmes. Epidemiologia e Prevenzione, 40(3-4), 243-248. https://doi.org/10.19191/EP16.3-4.P243.091.

Croucher, K., Wallace, A., \& Duffy, S. (2012). The influence of land use mix, density and urban design on health: A critical literature review (pp. 3-25). York, UK: The University of York.

D’Alessandro, D., Appolloni, L., \& Capasso, L. (2016). How wakable is the city? Application of the walking suitability index of the territory (T-WSI) to the city of Rieti (Lazio Region, Central Italy). Epidemiologia e Prevenzione, 40, 237-242.

D’Alessandro, D., Appolloni, L., \& Capasso, L. (2017a). Public Health and urban planning: A powerful alliance to be enhanced in Italy. Annali di Igiene, 29, 452-463.

D’Alessandro, D., Arletti, S., Azara, A., Buffoli, M., Capasso, L., Cappuccitti, A., et al. (2017b). Strategies for disease prevention and health promotion in urban areas: The Erice 50 Charter. Annali di Igiene, 29(6), 481-493. https://doi.org/10.7416/ai.2017.2179.

D’Alessandro, D., Buffoli, M., Capasso, L., Fara, G. M., Rebecchi, A., \& Capolongo, S. (2015). Green areas and public health: Improving wellbeing and physical activity in the urban context. Epidemiologia e Prevenzione, 39, 8-13.

Department for Communities and Local Government (DCLG). (2009). Multicriteria analysis: A manual London. http://eprints.lse.ac.uk/12761/1/Multi-criteria_Analysis.pdf.

European Institute for Design and Disability-EIDD. (2004). Stockholm Declaration. http:// dfaeurope.eu/what-is-dfa/dfa-documents/the-eidd-stockholm-declaration-2004/.

Fehr, R., \& Capolongo, S. (2016). Healing environment and urban health. Epidemiologia e Prevenzione, 40(3-4), 151-152. https://doi.org/10.19191/EP16.3-4.P151.080.

Galea, S., \& Vlahov, D. (2005). Urban health: Evidence, challenges, and directions. Annual Review of Public Health, 26(1), 341-365.

Gola, M., Capolongo, S., Signorelli, C., Buffoli, M., \& Rebecchi, A. (2017). Local health rules and building regulations: a survey on local hygiene and building regulations in Italian municipalities. Annali Istituto superiore di sanità, 53(3), 223-230. https://doi.org/10.4415/ANN_17_03_08.

Hickman, R., \& Banister, D. (2014). Transport, climate change and the city. London, UK: Routledge.

Talukder, S. Capon, A., Nath, D., Kolb, A., Jahan, S., \& Boufford, J. (2015). Urban health in the post-2015 agenda. Lancet, 385, 769.

Mosca, E. I., Herssens, J., Rebecchi, A., Froyen, H., \& Capolongo, S. (2019). "Design for All" manual: From users' needs to inclusive design strategies. Advances in Intelligent Systems and Computing, 824, 1724-1734.

Oppio, A., Bottero, M., Giordano, G., \& Arcidiacono, A. (2016). A multi-methodological evaluation approach for assessing the impact of neighbourhood quality on public health. Epidemiologia e Prevenzione, 40, 249-256. 
Rebecchi, A., Boati, L., Oppio, A., Buffoli, M., \& Capolongo, S. (2016). Measuring the expected increase in cycling in the city of Milan and evaluating the positive effects on the population's health status: A community-based urban planning experience. Annali di Igiene, 28(6), 381-391. https://doi.org/10.7416/ai.2016.2120.

Roy, B. (2013). Multicriteria methodology for decision aiding (Vol. 12). Springer Science \& Business Media.

World Health Organization. (2016). Health as the Pulse of the New Urban Agenda. United Nations Conference on Housing and Sustainable Urban Development. Quito, October 2016. Available online: http://apps.who.int/iris/bitstream/handle/10665/250367/9789241511445-eng. pdf;jsessionid=07F882D99F1E1AF399B57D5546EEB2BB?sequence=1.

World Health Organization. (2017). Towards more physical activity in cities transforming public spaces to promote physical activity —A key contributor to achieving the sustainable development goals in Europe. Copenhagen, Denmark: BMC Public Health.

Open Access This chapter is licensed under the terms of the Creative Commons Attribution 4.0 International License (http://creativecommons.org/licenses/by/4.0/), which permits use, sharing, adaptation, distribution and reproduction in any medium or format, as long as you give appropriate credit to the original author(s) and the source, provide a link to the Creative Commons license and indicate if changes were made.

The images or other third party material in this chapter are included in the chapter's Creative Commons license, unless indicated otherwise in a credit line to the material. If material is not included in the chapter's Creative Commons license and your intended use is not permitted by statutory regulation or exceeds the permitted use, you will need to obtain permission directly from the copyright holder.

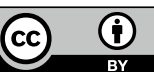

